\section{$\underset{\substack{\text { hommes } \\ \text { \& migrations }}}{ }$}

\section{Hommes \& migrations}

Revue française de référence sur les dynamiques

migratoires

1316 | 2017

L'islam en Europe

\title{
Fawaz Hussain, Orages pèlerins
}

Paris, Le serpent à plumes, 2016, 173 p., $17 €$.

\section{Mustapha Harzoune}

\section{Q OpenEdition \\ 1 Journals}

\section{Édition électronique}

URL : http://journals.openedition.org/hommesmigrations/3846

DOI : 10.4000/hommesmigrations.3846

ISSN : 2262-3353

\section{Éditeur}

Musée national de l'histoire de l'immigration

\section{Édition imprimée}

Date de publication : 1 mars 2017

Pagination : 199-200

ISBN : 978-2-919040-37-7

ISSN : $1142-852 X$

\section{Référence électronique}

Mustapha Harzoune, « Fawaz Hussain, Orages pèlerins », Hommes \& migrations [En ligne], 1316 | 2017, mis en ligne le 01 mars 2017, consulté le 24 septembre 2020. URL : http://journals.openedition.org/ hommesmigrations/3846; DOI : https://doi.org/10.4000/hommesmigrations.3846 
grations et les migrants [étaient] reconaus come une richesse, les positions dans le débat sur le degré d'ouverture des frontieres s'en trouveraient sans doute profontément modifies: touise Caron pointe la faiblesse des données sur les départs... de France. Or, l'étranger ne fait pas non plus automatiquement le pied de grue ou te siège du bourgeois! Peu chaut iे la Hittérature médiatico politique que 20 à $50 \%$ des immigrés repartent dans tes cing années qui suivent leur arrivée. Elle nevoit que ceuxquidébarquentet oculte ceux qui s'esbignent. Résultat, au lieu de réfléchir aux nouvelles mobilités (remigrations, passages, étapes, mouvements circulaires, adaptations au marché du travail international...), au lieu d'interroger les ressorts mut tifactoriels des migrations, au lieu de comprendre en quoiles trajectoires in teragissent sur ces facteurs de départ,

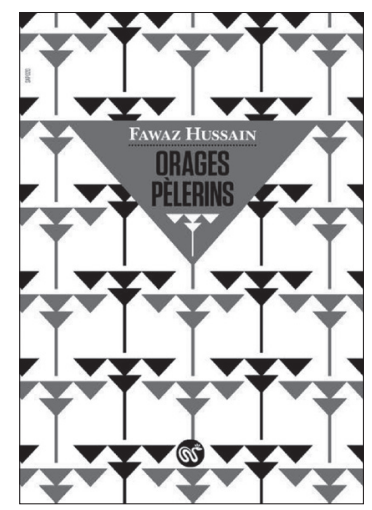

\section{Fawaz Hussain}

Orages pèlerins

Paris, Le Serpent à

Plumes, 2016, 173 p.,

$17 €$.

Ils sont quatre, quatre Kurdes, à s'aventurer sur les routes de l'exil. Ils sont quatre à partir pour échapper aux militaires, aux ayatollahs, aux rebelles kurdes, au racisme arabe, au déni culturel et linguistique. Au déni de leur humanité. Quatre à partir parce on continue d'associer immigration et invasion, immigration et intégration. Et de mentir. Car "sion ne s'intéresse qu'aux entrées on observe une progres sion nette entre 2006 et 2013. Anais lo prise en compte des sorties pernat de Auncer cette conclusion et l'Insee note whe forte baisse du solde migratoire glo bal [...], passant de 1712000 en 2006 à +33000 en 2013. :

te bilan est sans appel. Les politiques de contrôte- des frontières sont ineff eaces, contre productives, meurtrières, dispendieuses, immorales, elles favo risent mafias et trafies, pèsent sur la eohésion sociale, disqualifient le poli tique, valorisent les populismes. "Erise des migrants "? Non, crise des discours et des représentations. Crise du savoir. Et flasco de politiques qu'une formation sans imagination prétend simplement accentuer.

Mustapha Harzoune.

que les émigrés qui en reviennent paradent au volant de grosses voitures, se construisent des villas et épousent des " jouvencelles", parce que les passeurs, dealers de rêves, leur promettent l'Eldorado. Ils sont quatre pour qui l'échec marquerait l'humiliation. Ils sont quatre qui n'emportent qu'un maillot de corps, un caleçon, une paire de chaussettes, une chemise, de quoi se raser, un bout de miroir cassé, "pour se donner une apparence de propreté à son arrivée ». Ils sont quatre " pions sur l'échiquier noir et blanc de l'absurde »! Rien ne les distingue aux yeux extérieurs, indifférents 
ou hostiles. Et pourtant, les apparences cachent des êtres singuliers, des histoires et des désirs.

Dara, l'Irakien, s'en vient à Paris pour un visage, qu'il n'a vu qu'en photo. Pour le chercher et le trouver sous les traits de Ziba, une prostituée maghrébine. Oui, on peut partir par amour, par une sorte d'aspiration, un élan amoureux! Shérko, l'Iranien, quitte son " pays de mollahs et de femmes semblables à des sacs de charbon ambulants " pour vivre comme " un toutou choyé ». Du côté d'Auteuil, on promène son chien-chien à sa mémère, on ramasse ses crottes, on le porte tel un enfant, quand l'étranger crève sur son banc. Partir pour vivre comme un chien! Rustemé Zal, le naïf Syrien, aspire à retrouver une identité, à vivre quelques années de tranquillité, économiser un pécule et rentrer auprès de Tahmineh son épouse. Partir pour mieux s'en retourner! Enfin, il y a Sino, le Turc. Celui dont l'imaginaire est peuplé de rues et de lieux de Paris, de personnages échappés des romans français du xixe siècle. Partir par désir, non pour faire fortune, pour tutoyer la gloire dans la capitale de la culture!

Des quatre Kurdes, il est «le mieux préparé ». Lui parle français, sait remplir les formulaires de l'Ofpra, répondre aux questions, quitte à mentir. Pourquoi ne pas mentir quand, pour le recalé de l'asile, « la petite feuille de moins de vingt grammes [tombe] sur ses espérances aussi violemment que le couperet de la guillotine sur la nuque du condamné "?
Oui, ce qui se "joue ", c'est la vie ou la mort! Même si la mort d'un "clando" vaut "des clopinettes». Sino obtiendra le statut de réfugié. Un sur quatre.

Dès son arrivée, il s'habille de neuf et jette ses vieilles nippes, comme on se débarrasserait du passé, et file se gaver de charcuterie, de vin blanc et de bière. Pour mêler l'utile à l'agréable, il monte une entreprise de pompes funèbres ; façon d'assouvir ses fantasmes sexuels - attisés par la " morbidité du deuil » et les voiles noires des veuves - et d'assurer sa réussite. Lucide, Sino voit bien que les Kurdes brûlent "la chandelle par les deux bouts " et exercent des "métiers plutôt pénibles ". Ils vont " tomber comme des mouches, mais des mouches très sentimentales, car ils tenaient à être enterrés au Kurdistan. II y avait donc des milliards à gagner!".

Fawaz Hussain plonge le lecteur dans les anfractuosités où sont relégués les immigrés de Paris. Il passe de quartier en quartier, pousse les portes des piaules minables, s'incruste dans les hôtels de passes, scrute la sociologie, black et basanée, du métro parisien, pointe les bisbilles et les trafics communautaires. II décrit l'infortune du demandeur d'asile, les années à poireauter, la solitude, le doute, l'exploitation et la nostalgie pour les êtres laissés derrière soi. Les psychologies, les émotions, les failles ne sont pas factices. Ici, les hommes et les femmes ne sont pas de roman. Ils sont faits de chair et de sang. M. H. 